\title{
EFEITO DOS COMPLEXOS ENZIMÁTICOS CLARIFICANTES CLAREX E CEC1-CTAA SOBRE A QUALIDADE DO SUCO DE BANANA ${ }^{1}$
}

\author{
MARISA HELENA CARDOSO ${ }^{2}$, HILARY CASTLE DE MENEZES ${ }^{3}$, MARISA DE NAZARÉ HOELZ JACKIX4, \\ e ELISABETHBORGES GONÇALVES ${ }^{5}$
}

\begin{abstract}
RESUMO - Neste trabalho foi observado o efeito dos complexos enzimáticos clarificantes Clarex e CEC1-CTAA, adicionados na proporção de $0,03 \%$ v/p sobre purê de banana (Musa cavendishii), em condições amenas de hidrólise $\left(40^{\circ} \mathrm{C}, 15\right.$ minutos) visando determinar a qualidade, aqui representada pelos indicadores: rendimento; viscosidade; Brix; $\mathrm{pH}$; composição centesimal; contagens de bolores e leveduras e de mesófilos, e propriedades sensoriais de cor, aroma, sabor e corpo dos sucos de banana clarificados. O suco clarificado com Clarex apresentou-se significativamente $(\mathrm{p}<0,01)$ mais amarelo, menos cinza, menos opaco e menos viscoso do que o obtido com CEC1-CTAA. Não houve diferença significativa entre as médias de aroma de banana fresca e sabor nesses sucos. Além disso, os valores obtidos quanto a sabor, de ambos os sucos, foram considerados bons $(6,72$ e 6,05 com referência a sucos clarificados com Clarex e CEC1-CTAA, respectivamente), apresentando-se superiores ao centro da escala empregada, que variou de 0 a 10.
\end{abstract}

Termos para indexação: pectinases, processamento do suco.

\author{
EFFECT OF ENZYMATIC CLARIFIER COMPLEXES CLAREX \\ AND CEC1-CTAA ON THE QUALITY OF BANANA JUICE
}

\begin{abstract}
The effect of the clarifier enzymatic complexes Clarex and CEC1-CTAA, used in the proportion $0.03 \% \mathrm{v} / \mathrm{w}$ in industrialized banana (Musa cavendishii) pulp, at the conditions of gentle hydrolysis 40 degree Celsius, 15 minutes, was observed to determine the quality here represented by indicators such as yield, viscosity, Brix, $\mathrm{pH}$, centesimal composition, counts of moulds and yeasts and of mesophilics, and sensorial properties of color, aroma, flavor and body by both clarified banana juices. The juice clarified by Clarex was significantly $(p<0.01)$ more yellow, less grey, less opaque and less viscous than that obtained with CEC1-CTAA. There was no significant difference between the means of aroma of fresh banana and flavor in these juices. Furthermore, the values obtained for flavor for both juices were judged good (6.72 and 6.05 for the juices clarified with Clarex and CEC1- CTAA, respectively), because they were up the middle of the scale (from 0 to 10).
\end{abstract}

Index terms: pectinases, juice processing.

${ }^{1}$ Aceito para publicação em 14 de outubro de 1998.

${ }^{2}$ Eng a Alimentos, Dra , Curso de Engenharia de Alimentos, Universidade Estácio de Sá, Rua do Bispo, 83, Bloco L, CEP 20261-060 Rio de Janeiro, RJ. E-mail: mhelena@estacio.br

${ }^{3}$ Food Science, Dr ${ }^{\mathrm{a}}$, Dep. de Tecnologia de Alimentos, FEA, Unicamp, Caixa Postal 6121, CEP 13081-087 Campinas, SP. E-mail: hilary@fea.unicamp.br

${ }^{4}$ Eng ${ }^{\mathrm{a}}$ Alimentos, Drª , Dep. de Tecnologia de Alimentos, FEA, Unicamp.

${ }^{5}$ Estatística, Dra , Embrapa-Centro Nacional de Pesquisa de Tecnologia Agroindustrial de Alimentos (CTAA), Av. das Américas 29.501, CEP 23020-070 Guaratiba, RJ.

\section{INTRODUÇÃO}

Em 1995, o Brasil produziu 565.550 toneladas de banana, IBGE (1996). A Região Nordeste foi responsável por $40 \%$ da produção nacional de banana, destacando-se a Bahia como o maior Estado produtor. Outros $40 \%$ da produção ficaram com a Região Sudeste, Costa (1996).

Suco de banana clarificado industrializado é comumente encontrado nos mercados europeu, norte-americano e argentino, não estando disponível, entretanto, no mercado interno brasileiro. 
O processamento de suco a partir da polpa de banana compreende, inicialmente, hidrólise enzimática de carboidratos de cadeias longas, como, por exemplo, a pectina, a celulose e a hemicelulose nela presentes. O purê hidrolisado é então centrifugado, separando-se a fase líquida, a qual recebe o nome de suco clarificado. Em seqüência, o suco é "pasteurizado", embalado e armazenado.

A obtenção de suco clarificado de banana tem sido objeto de estudo por diversos pesquisadores (Dupaigne, 1974; Jaleel et al., 1978, 1979; Munyanganizi \& Coppens, 1974; Sreekantiah, 1975; Tocchini \& Lara, 1977; Yu \& Wu, 1987; Sims \& Bates, 1994). Esses autores têm proposto o emprego de complexos enzimáticos clarificantes (complexos procedentes de diferentes fabricantes) em diversas concentrações para obtê-lo, associado a tratamentos térmicos, tempos e temperaturas de hidrólise variados.

Basicamente, as condições de hidrólise enzimática têm variado de 30 minutos a 18 horas; temperatura de 21 a $50^{\circ} \mathrm{C}$; e concentração de enzimas de 0,01 a $0,6 \%$ v/p ou p/p (Garcia \& Rolz, 1974; Sreekantiah, 1975; Munyanganizi \& Coppens, 1976; Tocchini \& Lara, 1977; Víquez et al., 1981; Yu \& Wu, 1987; Pheentaveerat \& Anprung, 1993).

Clarex é um complexo enzimático clarificante que contém pectinase de origem fúngica (Aspergillus niger), normalmente empregado nos processamentos de frutas e vegetais e na fabricação de vinho. Apresenta atividade nas faixas de $\mathrm{pH}$ de 2,5 a 5,5 e de temperatura de 2 a $60^{\circ} \mathrm{C}$. O produto CEC1-CTAA também é um complexo enzimático clarificante, possui origem fúngica, e foi produzido pela Embrapa-Centro Nacional de Pesquisa de Tecnologia Agroindustrial de Alimentos (CTAA).

Os indicadores, também aqui referidos como propriedades ou atributos, escolhidos para comparar a qualidade dos sucos de banana, foram de natureza objetiva, tais como: rendimento; viscosidade aparente; Brix; pH; composição centesimal; valor calórico; contagens de bolores e leveduras e de mesófilos e de natureza subjetiva, realizada por provadores, sendo os atributos cor, aroma, sabor e corpo medidos através de escalas variando de zero a dez .

Este trabalho teve como objetivo comparar, com base nos indicadores acima referidos, a qualidade, dos sucos de banana clarificados, obtidos a partir de purê tratado pelos complexos enzimáticos clarificantes Clarex e CEC1- CTAA, empregando-se condições amenas de hidrólise.

\section{MATERIAL E MÉTODOS}

O purê de banana nanica (Musa cavendishii) foi cedido pela Duas Rodas Ltda. em latas contendo $3,4 \mathrm{~kg}$ de peso líquido. O processamento do purê compreendeu etapas como: lavagem das frutas, em estádio de maturação 6, correspondendo a bananas com cascas amarelas (Gous et al., 1987), em água clorada; descascamento manual; desintegração da polpa; homogeneização; desaeração, esterilização, resfriamento e enlatamento sob condições assépticas, de acordo com De Martin et al. (1972). As latas recravadas contendo purê foram mantidas a $25^{\circ} \mathrm{C}$.

Inicialmente, foram determinados composição centesimal, $\mathrm{pH}$, Brix do purê de banana industrializado, segundo métodos da Association of Official Analytical Chemists (1995), utilizando-se, para isto, quatro embalagens hermeticamente fechadas, originárias de lotes distintos de purê. Pesquisou-se a esterilidade comercial do produto através de procedimentos microbiológicos próprios para alimentos enlatados de baixa acidez, segundo o método 972.44 da Association of Official Analytical Chemists (1995).

Oito amostras de purê de banana, pesando $1.350 \mathrm{~g}$, foram aquecidas em banho-maria até $40^{\circ} \mathrm{C}$. A cada conjunto de quatro lotes adicionou-se um dos tipos de complexos enzimáticos clarificantes: um, comercial, denominado Clarex; e outro, denominado CEC1-CTAA, produzido pela da Embrapa-CTAA. Ambos os complexos enzimáticos foram empregados separadamente, na proporção de $0,03 \%$ $\mathrm{v} / \mathrm{p}$ sobre o purê. O experimento foi inteiramente casualisado nos dois tratamentos, com quatro repetições por tratamento.

As amostras dos dois tipos de mistura de purê e complexo enzimático clarificante foram mantidas sob agitação (1 rpm) durante a etapa de hidrólise enzimática, que foi realizada em banho-maria com termostato Fanem Mod. 100 , a $40^{\circ} \mathrm{C}$, por 15 minutos.

A centrifugação foi realizada à temperatura de $30^{\circ} \mathrm{C}$, com velocidade angular de $4.000 \mathrm{rpm}(3.951 \mathrm{~g})$, por 1 minuto e 30 segundos em centrífuga Sorvall RC-3B.

$\mathrm{O}$ rendimento do suco clarificado foi calculado em porcentagem $\mathrm{v} / \mathrm{p}$ em relação ao purê.

$\mathrm{O}$ suco foi então pasteurizado a $85^{\circ} \mathrm{C}$, por 1 minuto, em rotavapor Büchi RE 120 e envasado em garrafas de polietileno com tampa rosqueável.

Em seguida, foi resfriado rapidamente a $20^{\circ} \mathrm{C}$, separando-se amostras para serem avaliadas sensorialmente. 
Na seqüência, o suco foi congelado e mantido a $-18^{\circ} \mathrm{C}$, para análises quanto a suas propriedades químicas, físicas, fisico-químicas e microbiológicas.

As composições centesimais dos sucos e valores de Brix foram determinados segundo os métodos 920.152, 922.10, 925.36, 940.26, e 932.12 da Association of Official Analytical Chemists (1995).

As contagens microbiológica total e de bolores e leveduras foram realizadas de acordo com métodos descritos por Splittstoesser \& Mundt (1984).

Para medida do $\mathrm{pH}$ foi utilizado um potenciômetro Micronal Mod. B274 a $20^{\circ} \mathrm{C}$. Os valores de Brix foram tomados em refratômetro Shimadzu a $20^{\circ} \mathrm{C}$.

As viscosidades aparentes dos sucos foram obtidas em reômetro de cilindros concêntricos Contraves Mod. Rheomat 30, acoplado a programador Rheoscan 100, banho termostático Rheotherm 115 e registrador gráfico Rikadenki, a $40^{\circ} \mathrm{C}$

O procedimento para seleção dos provadores foi do tipo triangular, empregando-se diferentes concentrações de enzima Clarex $(0,03 \%$ e $0,025 \%$ v/p sobre o purê). O experimento foi repetido cinco vezes. Vinte e sete provadores com níveis de acerto iguais ou superiores a $60 \%$ foram selecionados. Apresentavam idades entre $18 \mathrm{e}$ 38 anos, sendo seis do sexo masculino e afirmaram gostar de banana. Eles avaliaram os sucos, através de método de escalas não-estruturadas, quanto aos atributos de cor (proporções de amarelo e cinza, grau de opacidade, com alta $=$ dez e baixa $=$ zero), aroma (de banana fresca, com forte $=$ dez e fraco $=$ zero), sabor (agradável $=$ dez e desagradável $=$ zero $)$ e corpo $($ denso $=$ dez e ralo $=$ zero $)$. Para as avaliações foram empregadas fichas com escalas não-estruturadas com extremos zero e dez. As avaliações de cor foram realizadas sob luz natural. O método estatístico empregado no estudo das respostas sensoriais foi a análise de variância paramétrica, com causas de variação provador e enzimas.

\section{RESULTADOS E DISCUSSÃO}

A Tabela 1 apresenta dados de composição centesimal, $\mathrm{pH}$, grau Brix e esterilidade comercial do purê de banana industrializado.

Segundo Franco (1982), $100 \mathrm{~g}$ de banana-nanica ou banana-d'água in natura contêm $76,5 \mathrm{~g}$ de umidade, $22 \mathrm{~g}$ de carboidratos, 1,3 g de proteínas e $0,2 \mathrm{~g}$ de lipídeos. A composição centesimal do purê empregado no presente trabalho esteve muito próxima da relatada por Franco (1982).

Víquez et al. (1981) empregaram escala de identificação de grau de maturação segundo o aspecto
TABELA 1. Resultados de análises químicas, física, físico-química e microbiológica de purê de banana industrializado ${ }^{1}$.

\begin{tabular}{|c|c|c|}
\hline Análises & Teor médio (\%) & $\mathrm{s}$ \\
\hline Umidade & 76,67 & 0,84 \\
\hline Carboidratos (por diferença) ${ }^{2}$ & 21,12 & - \\
\hline Proteínas & 1,01 & 0,07 \\
\hline Cinzas & 0,79 & 0,05 \\
\hline Lipídeos & 0,41 & 0,02 \\
\hline Fibra & 0,22 & 0,01 \\
\hline Valor calórico total & 92,21 & - \\
\hline Brix & 22,70 & 0,14 \\
\hline $\mathrm{pH}$ & 4,85 & 0,01 \\
\hline Esterilidade comercial & Estéril & - \\
\hline
\end{tabular}

${ }^{1}$ Média de quatro repetições.

${ }^{2}$ Inclui teor de fibra.

visual da casca da banana, citada por Gous et al. (1987). Compararam purês obtidos de bananas (Musa AAA cv. cavendishii gigante) completamente amarelas (grau 6), amarelas com pontos marrons (grau 7) e amarelas com manchas marrons (grau 8). Eles encontraram teores de umidade variando de 74,0 a $75,6 \%$, pH, de 4,85 a 5,10 e Brix, de 21,0 a $21,5^{\circ}$, em purês obtidos com bananas com graus 6 a 8 , respectivamente. No presente trabalho, verificaram-se: umidade um pouco superior ao de Víquez et al. (1981) em bananas amarelas com manchas marrons, mas próxima a de Franco (1982); pH idêntico ao encontrado por Víquez et al. (1981) em bananas completamente amarelas.

As embalagens, hermeticamente fechadas, não se apresentaram alteradas, quando mantidas a $35^{\circ} \mathrm{C}$ por dez dias, mostrando-se comercialmente estéreis.

A Tabela 2 contém medidas das propriedades físicas: rendimento, viscosidade, Brix e $\mathrm{pH}$ dos sucos.

Neste trabalho, em condições de hidrólise de $40^{\circ} \mathrm{C}$ por 15 minutos, empregando-se $0,03 \% \mathrm{v} / \mathrm{p}$ dos complexos enzimáticos Clarex e CEC1-CTAA sobre o purê centrifugado a $4.000 \mathrm{rpm}(3.951 \mathrm{G})$ por $1 \mathrm{minu}-$ to e 30 segundos, os rendimentos observados foram de 61,10 e $50,31 \% \mathrm{v} / \mathrm{p}$, respectivamente.

Os rendimentos $(\%)$, em relação à polpa, obtidos no processamento de suco de banana clarificado em experimentos realizados por diversos autores (Munyanganizi \& Coppens, 1976; Tocchini \& Lara, 1977; Víquez et al., 1981; Yu \& Wu, 1987) sob diferen- 
tes condições de hidrólise enzimática e de processamento em geral, com extrações realizadas por centrifugação ou prensagem, têm variado entre 68 e $80 \%$ e 60 e $90 \%$, respectivamente. Entretanto, na literatura consultada, apenas dois trabalhos apresentaram as condições exatas de centrifugação do purê hidrolisado, a saber: Víquez et al. (1981), (20 minutos, $4.000 \mathrm{rpm}$ correspondendo a $2.900 \mathrm{~g}$ ), e Yu \& Wu (1987), (20 minutos, $2.900 \mathrm{~g}$ ). Víquez et al. (1981), alcançaram rendimentos de $46,4 \mathrm{e} 48,9 \%$ de suco em relação à polpa, empregando $0,01 \% \mathrm{p} / \mathrm{p}$ de Ultrazym sobre purê de bananas (Musa AAA cv. cavendishii gigante) em estádio de maturação grau 7 durante 30 minutos a 35 e $45^{\circ} \mathrm{C}$, respectivamente. Yu \& $\mathrm{Wu}$ (1987) obtiveram rendimento de $52 \%$ de suco em relação à polpa empregando $0,01 \% \mathrm{p} / \mathrm{p}$ polpa de Rohapect $\mathrm{D}_{51}$ sobre polpa de banana madura (grau 7) durante 20 minutos, a $45^{\circ} \mathrm{C}$. Os resultados aqui alcançados, comparados aos obtidos por Víquez et al. (1981), foram considerados bons. Em relação aos demais autores pesquisados, na diferença de rendimento deve-se tomar em conta as condições de hidrólise deste trabalho, que foram amenas, assim, a desvantagem não tem significado.

Garcia \& Rolz (1974) em suco de banana var. Valery clarificado e concentrado a 49 e $53^{\circ}$ Brix encontraram as viscosidades de $13 \mathrm{cp}$ e $19 \mathrm{cp}$, respectivamente. Em suco de banana (Musa cavendshii gigante) clarificado, obtido a partir de purê apresentando $2.000 \mathrm{cp} \mathrm{a} 30^{\circ} \mathrm{C}$, ao qual se adicionou Ultrazym a $0,01 \%$, tendo sido a mistura homogeneizada por 10 minutos e centrifugada em centrífuga Alfa-Laval, mod. CRPX, Tocchini \& Lara (1977) encontraram viscosidade de $3,0 \mathrm{cp}$, Brix de $21^{\circ}$ e pH de 4,1. Não foi citado, entretanto, o valor de $g$. Segundo Víquez et al. (1981), em concentrações da enzima Ultrazym variando de 0 a $0,05 \% \mathrm{p} / \mathrm{p}$ de polpa aplicadas sobre $\mathrm{o}$ purê, incubando-se a mistura por 2 horas a $45^{\circ} \mathrm{C}$, e centrifugando-se por 20 minutos a $4.000 \mathrm{rpm}(2.900 \mathrm{~g})$, a viscosidade aparente encontrada nos sucos assim obtidos variou de 2 a $4 \mathrm{cp}$. Assim, as viscosidades obtidas neste trabalho foram consideradas: para Clarex, um pouco mais baixa que as encontradas por Tocchini \& Lara(1977)e Víquezetal.(1981); e, para CEC1-CTAA, mais alta que as desses autores.

Quanto ao Brix e ao $\mathrm{pH}$ dos sucos obtidos, os valores apresentaram-se bastante próximos aos encontrados por Tocchini \& Lara (1977) e Víquez et al. (1981).

Os resultados apresentados na Tabela 3 mostram diferenças consideradas desprezíveis quanto à composição centesimal dos sucos analisados.

TABELA 2. Valores observados de algumas propriedades físicas e pH dos sucos de banana clarificados segundo complexos enzimáticos clarificantes empregados ${ }^{1}$.

\begin{tabular}{|c|c|c|c|c|}
\hline \multirow[t]{2}{*}{ Propriedades } & \multicolumn{2}{|c|}{ Clarex } & \multicolumn{2}{|c|}{ CEC1-CTAA } \\
\hline & Média & $\mathrm{s}$ & Média & $\mathrm{s}$ \\
\hline Rendimento & 61,10 & 0,96 & 50,31 & 2,53 \\
\hline Viscosidade $^{2}$ & 2,31 & - & 8,78 & - \\
\hline Brix & 23,50 & 0,40 & 22,80 & 0,80 \\
\hline $\mathrm{pH}$ & 4,43 & 0,04 & 4,57 & 0,04 \\
\hline
\end{tabular}

${ }^{1}$ Média de quatro repetições.

${ }^{2} \mathrm{Em} \mathrm{cp}$, medida a $40^{\circ} \mathrm{C}$ para $\mathrm{D}=100 \mathrm{~s}^{-1}$; média de duas repetições.

TABELA 3. Resultados de análises químicas ${ }^{1}$ e microbiológicas ${ }^{2}$ realizadas nos sucos clarificados.

\begin{tabular}{|c|c|c|c|c|}
\hline \multirow[t]{2}{*}{ Análises } & \multicolumn{2}{|c|}{ Clarex } & \multicolumn{2}{|c|}{ CEC1-CTAA } \\
\hline & Média & $\mathrm{s}$ & Média & $\mathrm{S}$ \\
\hline Umidade & 77,90 & 0,62 & 77,48 & 0,42 \\
\hline Carboidratos totais (por diferença) & 20,50 & 0,50 & 20,98 & 0,42 \\
\hline Proteínas & 0,65 & 0,07 & 0,65 & 0,18 \\
\hline Cinzas & 0,61 & 0,05 & 0,59 & 0,03 \\
\hline Lipídeos & 0,34 & 0,01 & 0,30 & 0,15 \\
\hline Valor calórico & 87,66 & 2,19 & 89,22 & 2,29 \\
\hline Bolores e leveduras (UFC/g) & $<10 \mathrm{E} 1$ & - & $<10 \mathrm{E} 1$ & - \\
\hline Mesófilos (UFC/g) & $<10 \mathrm{E} 1$ & - & $<10 \mathrm{E} 1$ & - \\
\hline
\end{tabular}

${ }^{1}$ Média de quatro repetições.

${ }^{2}$ Média de duas repetições. 
De acordo com esses resultados, os sucos apresentaram conformidade com os padrões microbiológicos no Brasil (Brasil, 1997), em relação à contagem de bolores e leveduras, estando, portanto, aptos para o consumo. No Brasil, em sucos concentrados, adicionados ou não de conservadores, o limite máximo permitido para bolores e leveduras é de $10 \mathrm{E} 2 \mathrm{UFC} / \mathrm{g}$, ao passo que para sucos e refrescos in natura, o máximo é de $10 \mathrm{E} 4 \mathrm{UFC} / \mathrm{mL}$.

Os resultados para a contagem de bactérias mesófilas apresentaram-se baixos, embora a legislação brasileira não estabeleça padrão específico para isto. Em parte, isto se deve a que, em seguida à pasteurização, os sucos foram mantidos congelados até o momento de realização das análises, o que causou lesões nas células dos microorganismos.

Os resultados das análises de variância das respostas dadas pelos provadores na avaliação sensorial dos sucos clarificados quanto aos atributos de cor (proporções de amarelo e cinza; opacidade); aroma (de fruta fresca); sabor e corpo encontram-se na Tabela 4.

A Tabela 5 apresenta as médias das respostas dadas pelos provadores para cada uma das propriedades observadas nos sucos de banana clarificados.

Víquez et al. (1981) investigaram, em uma equipe de provadores, a preferência de suco de banana apresentando $\mathrm{pH}$ variando de 3,8 a 5,0 . O nível de $\mathrm{pH}$ foi ajustado com uma combinação de ácidos málico e cítrico. A faixa de $\mathrm{pH}$ preferida foi de 4,4 a 4,6. Os sucos apresentaram sabor e aroma excelentes. Yu \& Wu (1987) obtiveram, quanto ao suco de banana, as seguintes notas referentes a cor, aroma e sabor: 2,7, 3,4 e 4,1. Assim, as notas obtidas quanto a sabor dos sucos de banana clarificados com Clarex e CEC1-CTAA foram superiores às obtidas por esses autores. Ainda, não se julga que os sucos produzidos, em termos de $\mathrm{pH}$, deixem de ser bem aceitos, pois estão dentro da faixa detectada como preferida pela equipe de provadores de Víquez et al. (1981).
TABELA 4. Resultados das análises de variância das respostas dadas pelos provadores na avaliação sensorial dos sucos clarificados.

\begin{tabular}{lrrrrrr}
\hline Propriedades & \multicolumn{2}{c}{ Enzimas } & & \multicolumn{2}{c}{ Provadores } \\
\cline { 2 - 3 } & $\begin{array}{c}\text { Quadrado } \\
\text { médio }^{1}\end{array}$ & $\mathrm{~F}$ & & $\begin{array}{c}\text { Quadrado } \\
\text { médio }^{2}\end{array}$ & $\mathrm{~F}$ \\
\hline Proporção de amarelo & 134,11 & $34,67^{* *}$ & & 7,91 & 2,04 \\
Proporção de cinza & 154,02 & $25,12^{* *}$ & & 8,19 & 1,33 \\
Opacidade & 42,13 & $8,15^{* *}$ & & 8,29 & 1,60 \\
Aroma de banana fresca & 4,80 & 1,87 & & 12,52 & 4,88 \\
Sabor & 6,00 & 1,38 & & 5,66 & 1,30 \\
Corpo & 66,48 & $12,83^{* *}$ & & 5,43 & 1,04 \\
\hline
\end{tabular}

${ }^{1}$ Com 1 grau de liberdade.

${ }^{2}$ Com 26 graus de liberdade.

** Significativo a $1 \%$.

TABELA 5. Médias ${ }^{1}$ das respostas dos 27 provadores para atributos de qualidade observados nos sucos clarificados.

\begin{tabular}{lcc}
\hline Propriedades & Clarex & CEC1-CTAA \\
\hline Cor & & \\
Proporção de amarelo & $6,38 \mathrm{a}$ & $3,23 \mathrm{~b}$ \\
Propoção de cinza & $2,74 \mathrm{a}$ & $6,12 \mathrm{~b}$ \\
Opacidade & $5,26 \mathrm{a}$ & $7,03 \mathrm{~b}$ \\
Aroma de banana fresca & $5,34 \mathrm{a}$ & $4,75 \mathrm{a}$ \\
Sabor & $6,72 \mathrm{a}$ & $6,05 \mathrm{a}$ \\
Corpo & $4,23 \mathrm{a}$ & $6,49 \mathrm{~b}$ \\
\hline${ }^{1}$ Letras distintas numa mesma linha indicam diferença significativa entre
\end{tabular}

as médias a $1 \%$ de probabilidade.

\section{CONCLUSÕES}

1. O rendimento do suco CEC1-CTAA é cerca de $21 \%$ menor do que o do Clarex.

2. A viscosidade do suco CEC1-CTAA é 3,8 vezes maior do que a do suco Clarex.

3. O Brix do suco CEC1-CTAA é aproximadamente $3 \%$ menor do que o do Clarex.

4. $\mathrm{O} p H$ do suco CEC1-CTAA é cerca de $3 \%$ mais alto do que o do Clarex.

5. As composições centesimais dos sucos CEC1-CTAA e Clarex são semelhantes.

6. O suco CEC1-CTAA é menos amarelo, mais cinza e mais opaco que o suco Clarex.

7. Não há diferença entre as médias de aroma de banana fresca e a de sabor de ambos os sucos: apresentam-se superiores ao centro de uma escala que varia de 0 a 10.

8. Com a enzima Clarex, o produto é mais amarelo, menos cinza, com aroma mais acentuado de banana 
fresca, sabor mais agradável e mais encorpado, reunindo, portanto, os atributos de qualidade desejáveis no suco de banana clarificado.

\section{AGRADECIMENTOS}

À Indústria Duas Rodas Ltda e Solvay Enzimas, pela cessão do purê e do complexo enzimático clarificante Clarex; à Embrapa-CTAA, na pessoa da Dra. Sônia Couri, pela cessão do complexo enzimático clarificante CEC1-CTAA; à EmbrapaCTAA, pela realização das análises de composição centesimal, viscosidade e microbiológicas; e aos corpos discente, docente e administrativo da Escola de Nutrição da UNI-RIO/RJ, pelas avaliações sensoriais dos sucos.

\section{REFERÊNCIAS}

ASSOCIATION OF OFFICIAL ANALYTICAL CHEMISTS. Official methods of analysis. 16.ed. Arlington, Virginia, 1995. ch.17, p.41-42, ch.37. 23p.

BRASIL. Ministério da Saúde. Secretaria de Vigilância Sanitária. Portaria n ${ }^{\circ} 451$, de 19 de setembro de 1997. Aprova o Regulamento Técnico de Princípios Gerais para o Estabelecimento de Critérios e Padrões Microbiológicos para Alimentos. Diário Oficial da República Federativa do Brasil, Brasília, n.182, p.21007, Seção 1, 1997.

COSTA, I.L. A produção de frutas tropicais na Bahia. Agroanalysis, v.16, n.2, p.22-25, 1996.

DE MARTIN, Z.; BLEINROTH, E.W.; MARSAIOLI JUNIOR, A. Industrialização da banana. Boletim do ITAL, v. 32, p.39-69, 1972.

DUPAIGNE, P. A propos de l'extraction d'un jus de banane, en vue de la production de la bière de banana. Fruits, v.29, n.12, p.821-822, 1974.

FRANCO, Nutrição. 6.ed. Rio de Janeiro: Atheneu, 1982. p. 138.

GARCIA, R.; ROLZ, C. Reological properties of some tropical fruits products and their enzimic clarification. INTERNATIONAL CONGRESS FOOD SCIENCE AND TECHNOLOGY, 4., 1974, Guatemala City. Proceedings... Guatemala City: ICAITI, 1974, v.2, p.18-26.

GOUS, F.; WYK, P.J.; McGILL, A.E.J. The use of commercial enzymes in the processing of bananas. Lebensmittel - Wissenschaft und Technologie, v.20, p.229-232, 1987.

Pesq. agropec. bras., Brasília, v.34, n.5, p.849-854, maio 1999
IBGE. Síntese estatística: produção anual das lavouras e área. Agroanalysis, Rio de Janeiro, v.15, n.7, p.3637, 1996 .

JALEEL, S.A.; BASAPPA, S.C.; RAMESH, A.; SREEKANTIAH, K.R. Developmental studies on enzymatic processing of banana (Musa cavendishii). II. Pilot scale investigations. Indian Food Packer, v.33, n.1, p.10-14, 1979.

JALEEL, S.A.; BASAPPA, S.C.; SREEKANTIAH, K.R. Developmental studies on certain aspects of enzymic processing of banana (Musa cavendishii). I. Laboratory investigations. Indian Food Packer, v.32, n.2, p.17-20, 1978.

MUNYANGANIZI, B.; COPPENS, R. Étude comparative de deux procédés d'extraction du jus de banane appliqués à deux variétés différentes. Industries Alimentaires et Agricoles, v.93, p.707-711, 1976.

MUNYANGANIZI, T.; COPPENS, R. Extraction of banana juice. Industries Alimentaires et Agricoles, v.91, n.3, p.185-191, 1974.

PheENTAVEERAT, A.; ANPRUNG, P. Effect of pectinases, cellulases and amylases on production of banana juice. Food, v.23, n.3, p.188-196, 1993.

SIMS, C.A.; BATES, R.P. Challenges to processing tropical fruit juices: banana as an example. Proceedings of the Florida State Horticultural Society, v.107, p.315-319, 1994.

SPLITTSTOESSER, D.F.; MUNDT, O. Fruits and vegetables. In: SPECK, M.L. (Ed.). Compendium of methods for the microbiological examination of foods. Washington: American Public Health Association, 1984. ch.46, p.636-643.

SREEKANTIAH, K.R. Nature and application of pectinases with special reference to fruit and vegetable processing industry. Indian Food Packer, v.29, n.4, p.22-36, 1975.

TOCCHINI, R.P.; LARA, J.C.C. Industrialização de suco de banana simples e concentrado. Boletim do ITAL, v.51, p.93-112, 1977.

VÍQUEZ, F.; LASTRETO, C.; COOKE, R.D. A study of the production of clarified banana juice using pectinolytic enzymes. Journal of Food Technology, v.16, p.115-125, 1981.

YU, T.H.; WU, C.M. Production of clarified banana juice using pectinolytic enzymes. Food Science, v.14, n.3, p.154-164, 1987. 